Letters to the Editor

\title{
Group Separation of Linear DNAs and Circular DNAs by Curdlan Gel Electrophoresis
}

\author{
Kenji Hamase, Hiroshi Nakamura ${ }^{\dagger}$ and Terumi Nakajima \\ Department of Analytical Chemistry, Faculty of Pharmaceutical Sciences, The. University of Tokyo, \\ Hongo, Tokyo 113, Japan
}

Keywords Curdlan, gel electrophoresis, agarose, linear DNA, circular DNA, group separation

We have recently demonstrated that curdlan $(\beta-1,3-$ glucan) gel has an excellent ability of molecular recognition in the gel electrophoresis of some low molecular weight compounds. ${ }^{1}$ Curdlan gel is as effective for the separation of proteins as sodium dodecyl sulfate polyacrylamide gel electrophoresis (SDSPAGE). ${ }^{2}$ In the present communication, we will report on simple group separation of linear DNAs and circular DNAs by curdlan gel electrophoresis, which cannot be achieved by any conventional methods.

\section{Experimental}

\section{Materials}

Curdlan was purchased from Wako Pure Chemicals (Osaka, Japan). Agarose for electrophoresis was purchased from Nacalai Tesque (Kyoto, Japan). DNAs and EcoRl solutions were purchased from Takara (Kyoto, Japan). Water was purified using a Milli-Q reagent system (Millipore, Bedford, MA, USA). The other reagents and buffers used were of guaranteed grade.

\section{Preparation of DNA solutions}

Stock solution of DNAs were prepared with water to make $0.2 \mu \mathrm{g} / \mu \mathrm{l}$ solutions. Before being applied to the gel, the sample solution $(3-10 \mu \mathrm{l})$ was diluted with an equal volume of a sample buffer $(90 \mathrm{mM}$ Tris- $90 \mathrm{mM}$ boric acid-1 mM EDTA-0.1\% Phenol Red-50\% glycerol).

\section{Enzymatic conversion of circular DNAs to the corresponding linear DNAs}

Circular DNAs (pUC19 and ColE1) were digested with restriction enzyme (EcoR1) according to the method described by Maniatis et al. ${ }^{3}$ A $25 \mu$ l-portion of a circular DNA solution (equivalent to $25 \mu \mathrm{g}$ of DNA) was mixed with $25 \mu$ l of a buffer solution $(500 \mathrm{mM}$ Tris- $\mathrm{HCl}$

\footnotetext{
t To whom correspondence should be addressed.
}

at pH 7.5-100 mM $\mathrm{MgCl}_{2}-10 \mathrm{mM}$ dithiothreitol-1000 $\mathrm{mM} \mathrm{NaCl}), 10 \mu \mathrm{l}$ of EcoR1 solution (120 units) and 190 $\mu l$ of water. The mixture was incubated at $37^{\circ} \mathrm{C}$ for $4 \mathrm{~h} ; 500 \mu \mathrm{l}$ of ethanol was added and the solution was frozen at $-20^{\circ} \mathrm{C}$ for $1 \mathrm{~h}$. After centrifugation at $15000 \mathrm{~g}$ and $0^{\circ} \mathrm{C}$ for $20 \mathrm{~min}$, the supernatant was removed and the precipitated linear DNA was washed with $70 \%$ ethanol. After removal of ethanol, the DNA was redissolved in water at a concentration of $0.2 \mu \mathrm{g} / \mu \mathrm{l}$.

\section{Preparation of gel}

Agarose gel was prepared by a conventional method. ${ }^{4}$ Curdlan gel was prepared by the method described by Kusui. ${ }^{5}$

\section{Gel electrophoresis}

A submarine gel electrophoresis system (Nihon Eido, Tokyo, Japan) was used. ${ }^{4}$ The electrophoresis was conducted with $90 \mathrm{mM}$ Tris- $90 \mathrm{mM}$ boric acid- $1 \mathrm{mM}$ EDTA (pH 8.4) at constant voltage $(100-300 \mathrm{~V})$. After electrophoresis, DNAs were detected with ethidium bromide fluorescent staining.

\section{Results and Discussion}

Figure 1 shows the relations between the logarithm of the molecular weight and the electrophoretic velocity $\mu$, defined by velocity $\left(\mathrm{cm} \mathrm{h}^{-1}\right)$ per electric field $\left(\mathrm{V} \mathrm{cm}^{-1}\right)$, of four kinds of linear DNA. The figure indicates that curdlan gel can be used as a support for electrophoresis of linear DNAs with almost equal performance to that of agarose gel. Furthermore, curdlan gel exhibited a unique property in the electrophoresis of circular DNAs. In curdlan gel, circular DNAs hardly migrated at any gel concentrations, whereas circular DNAs freely migrated in agarose gel (Fig. 2). Figure 3 shows the typical electropherograms of circular DNAs (pUC19 and ColE1) and their EcoR1 ${ }^{6}$ digests obtained with curdlan and agarose gel. While the agarose gel enabled the excellent separation of various conformers of circular DNAs such 

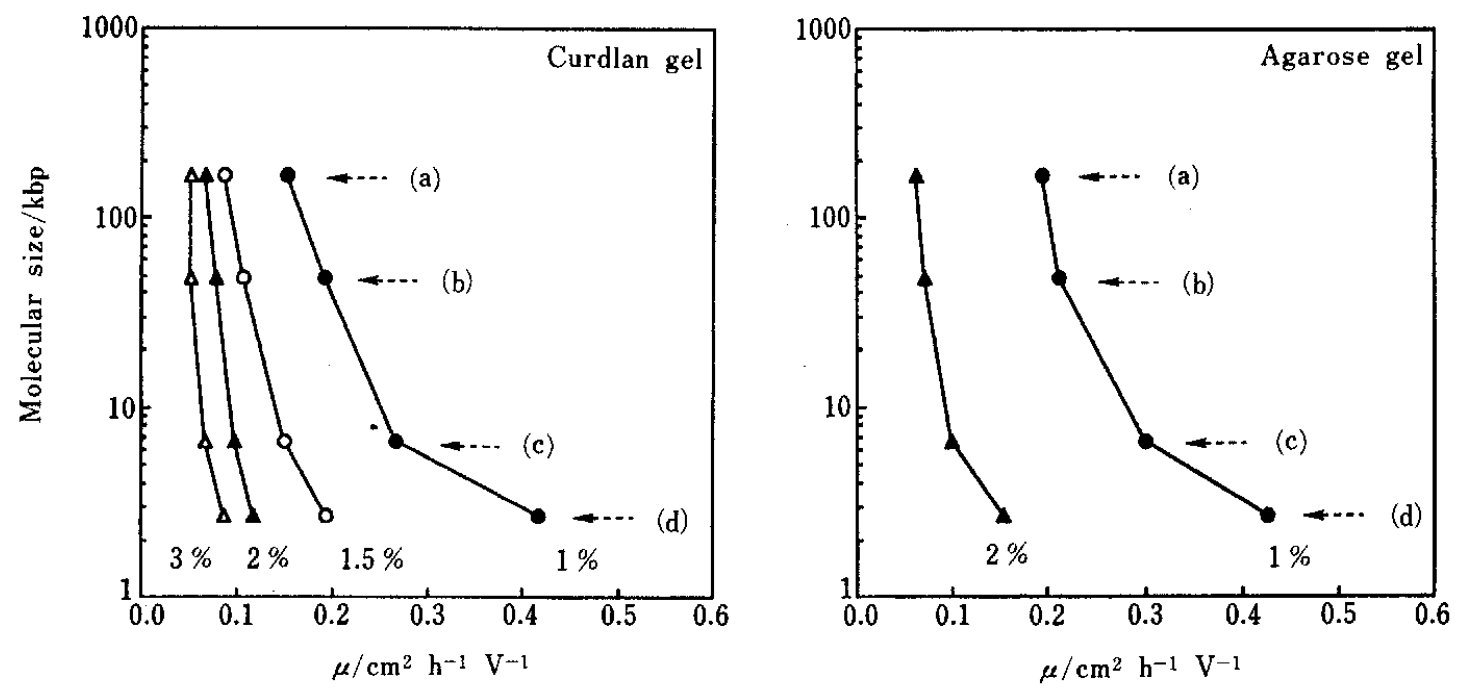

Fig. 1 Relationship between logarithm of molecular size and electrophoretic velocity $\mu$. Electrophoresis mode, constant voltage ( $100 \mathrm{~V}$ ); buffer, $90 \mathrm{mM}$ Tris $-90 \mathrm{mM}$ boric acid-1 mM EDTA (pH 8.4); samples, (a) T4dC DNA (166 kbp), (b) $\lambda$ DNA (48.5 kbp), (c) ColE1 EcoR1 digest (6.6 kbp), (d) pUC19 EcoR1 digest $(2.7 \mathrm{kbp})$.
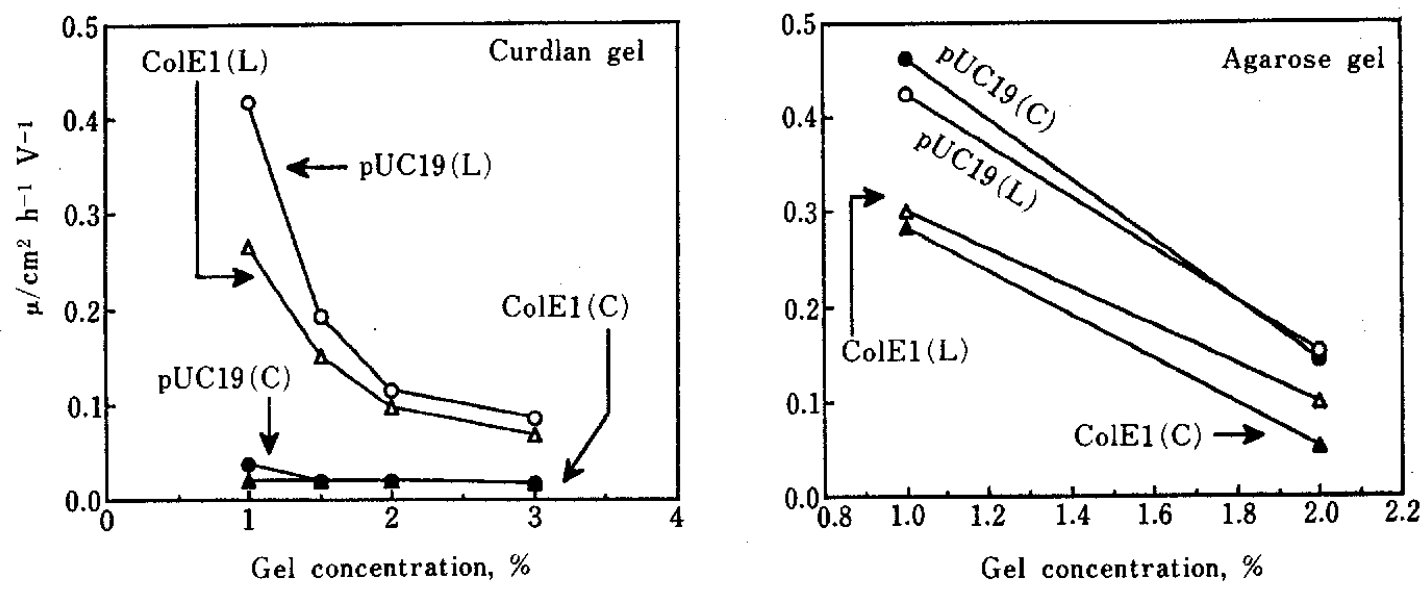

Fig. 2 Electrophoresis of linear and circular DNAs. Conditions are the same as in Fig. 1. (L), linear; (C), circular.
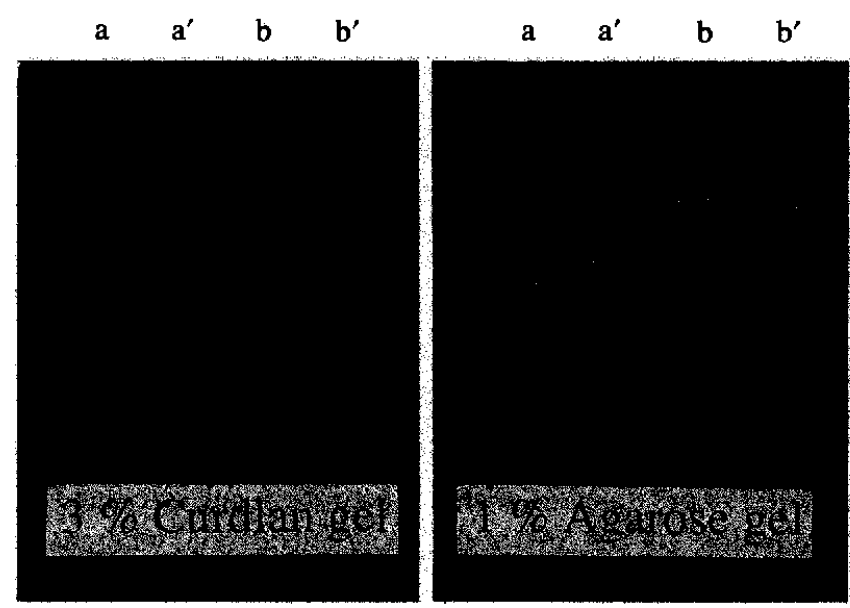

Fig. 3 Electrophoresis of linear and circular DNAs. Electrophoresis mode, constant voltage (curdlan $300 \mathrm{~V}$, agarose $100 \mathrm{~V}$ ); buffer, $90 \mathrm{mM}$ Tris-90 mM boric acid-1 mM EDTA (pH 8.4); samples, (a) pUC19 (2.7 kbp), (a') pUC19 EcoR1 digest (2.7 kbp), (b) ColE1 (6.6 kbp), (b') ColE1 EcoR1 digest $(6.6 \mathrm{kbp})$. 
as supercoiled DNA and relaxed DNA, the curdlan gel did not give fine resolution. However, the results in Figs. 2 and 3 clearly suggest that curdlan gel can recognize the difference in shape between linear DNAs and circular DNAs, though the retention mechanism of the latter remains unsolved.

For the group separation of circular DNAs and linear DNAs, only the sucrose density gradient centrifugation method $^{7}$ is available at present. However, this method requires skillful techniques, special apparatus and a long time for centrifugation. Therefore, the present findings will be extremely useful for separation of plasmid from genome DNAs, which is a key procedure in gene technology.

\section{References and Note}

1. K. Hamase, H. Nakamura and T. Nakajima, Anal. Sci., 7,
811 (1991).

2. K. Hamase, H. Nakamura, T. Nakajima, Anal. Sci., 8, 699 (1992).

3. T. Maniatis, E. Fritsch, J. Sambrook, "Molecular Cloning", Cold Spring Harbor Laboratory, New York, 1982.

4. J. Sambrook, E. Fritsch, T. Maniatis, "Molecular Cloning", 2nd ed., Cold Spring Harber Laboratory, New York, 1989.

5. S. Kusui, Gekkan Fudo Kemikaru, 5, 3 (1989).

6. The enzyme EcoR1 splits only one site of the circular DNA to produce the linear DNA with practically the same molecular weight.

7. R. Rodloff, W. Bauer, J. Vinograd, Proc. Natl. Acad. Sci. U.S.A., 57, 1514 (1967).

(Received September 10, 1992)

(Accepted October 22, 1992) 